\title{
COLLABORATIVE TRAINING FOR TEACHING PROBABILITY AND STATISTICS: EMPIRICAL APPROACHES AND SIMULATION WITH ELEMENTARY SCHOOL STUDENTS
}

\author{
Leandro de Oliveira Souza \\ Universidade Federal do Amazonas, Brazil \\ olileo@ig.com.br
}

This paper presents a discussion of a case study conducted with the voluntary participation of sixteen mathematics teachers in the final years of elementary school in the state of São Paulo, Brazil. Research has shown that mathematics teachers feel insecure and sometimes use a linear and deterministic approach to teaching statistics. Based on this problem, a collaborative action research project has been developed. We analyze one of the activities planned in pairs and implemented by one of the teachers. Participants developed empirical activities on probabilistic and statistical themes and planned lessons with a focus on problem solving by simulation. It was evident that the teacher was a producer of knowledge that mobilizes that knowledge for the sake of generating teaching situations that promote student learning. During the teaching process, students misconceived luck, chance and causality, requiring the teacher to manage the process that allowed them to re-elaborate these ideas.

\section{INTRODUCTION}

The integration of statistical analysis with probabilistic distributions and the assumptions underlying these models are still real puzzles in teaching (Pfannkuck, 2005). We identified, through questionnaires, that teachers were reluctant to introduce concepts of probability in elementary education, and that it is often due to lack of knowledge about the connections between probability and statistics.

Probability can be difficult to learn and teach, due to the special characteristics involved in looking more deeply at broader issues through data analysis, making value judgments about the appropriate models for looking at data, and mainly going through the process of reflection on controversial ideas such as chance and causality (Souza and Lopes, 2011). In Stohl's opinion (2005), the improvement of the teaching of probability must include both the understanding of statistical concepts, and reflection on the deterministic and non-deterministic nature of the world.

In this paper, we analyze a probabilistic simulation activity that was designed and planned by a pair of teachers participating in continuing education, which was then applied to a class of students, and then analyzed and communicated to the group in training by one of the teachers. Our goal was to build data for a collaborative training program so that, through observation of teaching activities, we could understand how the development, planning and implementation of a probabilistic simulation activity, after a cycle of workshops, would modify the pedagogical approaches and attitudes of teachers during the teaching process. The analysis was done using questionnaires completed during training and video-recordings of the meetings.

The training was based on an action research proposal based on the collaborative work of sixteen mathematics teachers who teach students in the final years of elementary school (aged 1014). In pairs, they developed educational activities targeted to their students beginning with a problem that required the collection of data for analysis and understanding of the problem. To do so, we exposed the teachers to an initial phase of workshops where they studied and participated in empirical activities and were exposed to Wild \& Pfannkuch's (1999) model that describes the statistical reasoning processes in research environments. During the planning phase, teachers were instructed to use the strategies outlined in the model, so that they would lead students to infer starting with a problem, then planning, collecting data, building charts, analyzing and finally drawing conclusions about the proposed problem.

Last, we discuss evidence that shows how the training program helped to modify the conceptual view of the teachers on how to approach probability content.

\section{TEACHER TRAINING FOR STATISTICS EDUCATION}

The current situation of statistics teaching reinforces the need to investigate appropriate and efficient ways to improve the mathematical and professional knowledge of teachers, leading

In: M.A. Sorto (Ed.), Advances in statistics education: developments, experiences and assessments. Proceedings of the Satellite conference of the International Association for Statistical Education (IASE), 
them to have pedagogical mastery of investigative approaches, empirical activities and production of information guided by data analysis. In the view of Batanero and Diaz (2012), just as students build their knowledge in an active way, through problem solving and interaction with classmates, teachers should be prepared for teaching, especially if we expect them to use a constructivist and social approach in the classroom. We also believe (Soares \& Goulart, 2008) that the sharing of lessons and the analysis of the results obtained by teachers can generate original ways of acting and thinking that will be absorbed and given new meaning in the future. Training teachers to utilize statistical research strategies, probabilistic simulations and games in their classrooms can be extremely useful, so that the students can learn how to create arguments, based on evidence, and make informed decisions on data that drive them to a smaller chance of error.

It is important to allow teachers to have more responsibility and more autonomy in their own training, so that they have support to develop creativity and critical thinking. Teachers who teach statistics do not necessarily need to build only statistical concepts, but also need to understand how students develop their reasoning (Pfannkuck, 2008). In addition, they need to learn different ways to prepare and use activities that stimulate

In this study, when we analyzed a lesson developed and implemented by a pair of teachers, we found that the training program was essential to develop the perception of these teachers about the various forms of reasoning of their students, allowing them to redirect pedagogical activities when necessary. We describe the training and research methodology that we have adopted to help teachers participating in the research to modify their approaches to teaching.

\section{METHODOLOGY}

This case study refers to action research conducted during a $\mathrm{PhD}$ program. Here, we assume the perspective of Barbier (2004), which considers action research as a process conceived and decided upon by the researcher to facilitate intentional changes in teachers' practice. Actions are priority in this type of research; however, during the training process, the researchers explore the consequences of actions for the purpose of academic research. We chose to analyze and collect data during the process of collaborative training that, for Tripp (2005), is the process by which people work together as co-researchers on a project where everyone has equal participation.

According to Barbier (2004), this type of research begins in the context of a group in crisis, since researchers cannot cause it to happen. The problem of teacher training in the teaching of statistics was caused by the statistical content of the information processing block that has recently been introduced into the Brazilian curriculum. Therefore, our aim with the training was to help all involved to be aware of the most important concepts to be taught so that they could develop a collective action to improve their own practice.

In this project, the action research was designed to encourage intentional changes in teaching technique decided by the researchers. There were sixteen mathematics teachers who participated voluntarily in the study. They taught students in the later years of elementary school in the municipality of São José dos Campos in São Paulo. They attended eleven bi-weekly meetings that lasted two and a half hours.

The meetings were divided into three phases - workshops, planning and communication. The first phase consisted of workshops over the course of four meetings in which teachers had their first contact with investigative approaches and technological resources (Fathom software and free internet applications) for teaching statistics. The second phase was also organized into four meetings. In this phase, we randomly selected statistics and probability content so that teachers could develop and plan a lesson in pairs with pedagogical assistance from the researcher. After that, we asked the teachers to develop the planned lesson with a group of students making notes of their observations to pass the experience back to the whole group. The last phase consisted of the communication. In this phase, the teachers did the sharing of the exercise, clarifying how the development of the lesson that was planned and implemented occurred by communicating the observations made during the class and explaining how they acted in the teaching process during the answers from their students. In the process of discussion and reflection, the teachers themselves listed actions that were beneficial to the teaching and learning process and those that were not.

Early on at the first meeting, data from the teachers was collected through an initial questionnaire, with the goal of helping us understand the professional experiences that they had in teaching statistics, and also their personal educational experiences with regard to this matter in 
their undergraduate courses. In addition, we sought to know what kind of teaching approaches they used in their classrooms. Five more questionnaires, all with open questions, were distributed throughout the sessions, for a total of 40 questions. These questionnaires were designed to understand how teachers saw the teaching of statistics compared to the teaching of mathematics. In addition, we assessed, through a self-evaluation, what kind of teaching approaches teachers used in their classes, how they were feeling about teaching statistics using a process focused on research and data collection, and finally what changes had occurred in their teaching practice after participating in the project team. All meetings were recorded on video recordings that were also used in the analysis.

In response to our goal of understanding how the development, planning, implementation and communication of a lesson of probabilistic simulation would modify the teaching approaches and attitudes during the teaching process, we analyzed a case study in this paper. The focus was on two periods of the training: first, the questionnaires applied in the workshop phase that have brought to light the practical needs of teachers with regard to teaching statistics; and second, the planning, implementation and communication phases of a lesson by one of the teachers.

\section{DEVELOPMENT PROCESS}

At the beginning of the project, Alice, who has about three years of teaching experience and a degree in mathematics, claimed to be clear on all topics that must be presented in elementary education, pointing out the main themes that are described in the Brazilian Curricular Parameters PCN (Ministério da Educação, 1998). Additionally, she revealed that she had never read anything about the information processing theme (combinatorics, probability, statistics), because she had not attended a continuing education course that dealt with this. She also commented that in their initial training, the approach had been practically based on the problem solving paradigm.

In the first questionnaire, we asked teachers about how content related to statistics was given in their initial (undergraduate) training. Alice reported: "The methodology used was to fill tables, calculate average, standard deviation and construct graphs using paper for this. There has never been any attention to inference or the teaching methodology that would be passed on to students." On technological resources, Alice confirmed: "I never had contact with any software to teach statistics, although I had already used software to teach the four basic operations and first degree equations."

We asked in which grade level she normally introduced statistics. The teacher replied: "I teach 9th grade, but this is the first year that I am teaching this grade level and have not come to this content yet. In fact, I have never actually taught statistics". This statement is not totally at odds with the PCN of mathematics, because they do not indicate the grade level in which the content should be introduced, only the cycles (high-level groupings of grade levels). However, the assertion of the teacher shows that this content may be addressed by some teachers only in the final grade level of elementary school, and this indicates that statistics and probability may be being treated as separate content, with no relation to the other blocks, which is not recommended. When asked about the obstacles she encountered to teach this subject, the teacher replied: "In my training, I learned the content, however I did not learn how to approach it and so do not feel prepared." Regarding her expectations about the training, Alice said: "I hope to refresh my mind about statistics. It's been long since I studied this subject. I hope to learn methodologies that contribute to the dynamics of my classes and learn how to use useful software to address statistics."

In the initial questionnaire, in general, we confirmed that besides having learned statistics in a procedural way, teachers reported feeling insecure about teaching this subject. Alice's responses were very similar to those of the other teachers in the group.

About how Alice saw the differences between teaching statistics and mathematics, she said: "[ ] ... I believe that statistics is within mathematics. Statistics deals more with data collection, research and interpretation, while mathematics has more to do with algebra." (Alice, May 19, 2011)

Regarding teaching methodology, she believed: "[...] The best way to teach statistics is through fieldwork so that students are participating agents, building surveys, collecting data, designing, transforming and drawing conclusions about information" (Alice, May 19, 2011). Furthermore, she believed that probability and technological resources could be of fundamental importance. Teaching statistics through projects is discussed by Batanero and Diaz (2011). 
There were many difficulties in modifying teaching approaches, which was pointed out by the group in training. To prepare a lesson that they considered to be good, they lacked the mastery of content, availability of simple and appropriate teaching materials, time for planning (which, in most cases, was done alone at home) and available computer equipment.

Based upon the story of Alice and other teachers in the initial phase of research, we believe that in many Brazilian universities, statistics is still taught in a procedural, hierarchical, linear and traditional way. It is very likely that this educational perspective described by teachers implies, for them, pedagogical difficulties to contextualize the content of statistics and apply them to problems in the students' reality, in the same way as real problems that permeate other sciences.

In the next section, we will describe how Alice's activity was planned and developed in collaboration with another teacher, twenty years more experienced, who was randomly chosen. In addition to this lesson, the process of collaborative action research that we applied generated six other lessons planned by teachers, and each was subjected to individual analysis. We chose to discuss the activity performed by this pair, since it was planned and implemented by a teacher who had recently graduated, which allowed us to analyze data from a teacher who had just recently gotten out of college. We believe that by being a recent graduate, this teacher would be less likely to have her approach and vision influenced by problems that permeate the teaching practice within the school system.

\section{PLANNING AND IMPLEMENTATION PHASE}

The planning and construction of the activity of the pair of teachers began with the topic Urn and Roulette Probability. The pair at first searched the internet for some software that could assist them in planning the lesson. As both found only one application with a tutorial classified for high school, they struggled to adapt it to elementary school and gave up on using it. The major complication for the pair was that the graphics system of the software was not visually clear and, moreover, it treated probability in such a way that did not allow for the exploration of data collected. Basically, the application simulated the picking of colored balls from an urn, building a chart with columns containing the chosen balls.

In general, we realized that teachers needed more time to adapt to the tools. Furthermore, they complained that they could not find anything like it in textbooks. Activities found there, most of the time, dealt only with the interpretation of charts and tables, calculating and reading, leaving aside important concepts such as the study of the variation, the context of the problem at hand and relations of probability with statistics.

Because the software was not accepted by teachers, we suggested that they plan an activity that would use real materials, for example, colored balls and opaque bags. Thus it would be possible to understand the law of large numbers through actual simulation. We proposed that they build graphs from data collected by the students in groups and to add more data gradually accordingly to the color of each ball picked from the bag, so they could make observations and inferences during the construction of the graphs.

After the suggestions, the pair decided that they would not use any software and started planning an activity. At first, they thought about doing a simulation where they would put three green balls and seven red balls in an opaque bag, so that students would know neither the number nor the color of the balls.

In pairs, students (about 12 years old) would pick a ball, note its color in a table, return it to the bag, mix and take another ball, also noting its color. This procedure would be repeated at least 20 times for each pair. After completing each table, the teachers would add the data collected to construct a graph on the blackboard, asking the students, during construction, about which ball had been taken out more often.

In theory, this process would help students in the cognitive construction of probability skills. Probably, after some balls had been picked from the bag, students would be able to say for sure which color occurred more often. The initial idea was to increase the number of picks gradually, noting them in a table, transforming the results into a percentage to then construct a bar chart or a pie chart with the results. While this process of construction was taking place, the teachers, with some pre-prepared questions in hand, would lead the cognitive development of students, so that they could predict the percentage of balls of each color, after a series of picks. 
With the initial plans outlined, we then suggested that the teachers take advantage of this activity to introduce issues of gambling. When they accepted, they suggested allowing students to make bets, using fake bank notes. The idea was that, with the room divided into pairs and after revealing how many balls of each color were in the bags, all the students would reach a consensus and bet on the green balls or the red balls. The teacher would bet on the color not chosen by the students.

The rule of the game would be: Every time that a green ball was selected, the bettor who had chosen it would receive $\mathrm{R} \$ 16.00$ from the opponent, and every time a red ball was selected, the bettor would pay R $\$ 8.00$. The question in this case would be: Who will win the most money?

There were three green balls and seven red balls in the bag. It was predicted that after 100 picks, for example, those who had chosen the red balls would get around $\mathrm{R} \$ 560.00$ (70 x 8), while those who had opted for the green balls would get around $\mathrm{R} \$ 480.00$ (30 x 16). Encouraging students to reason about the bets, teachers would propose the simulation a few more times. After that, they would lead students through questions to predict the results of bets, demystifying the idea of luck when the game does not provide equal chances for both players.

The goal of the activity outlined by the teachers would be to lead students to understand that even if they could sometimes win the bet, knowing the rules of the game and betting on the right color would give them control of the situation and allow them to earn much more money than they would lose, according to the number of balls picked. Following this plan, students would be prepared to empirically understand the law of large numbers - "the first fundamental theorem of probability." The communication phase about how was the activity approached by the teacher and our analisys on that are described in Souza, Faccio \& Lopes (2014). In the previously referenced paper, the reader can have a wide view about the process conducted by the teacher, also is possible to see how investigations questions were presented to students. The need to use probability emerged during the implementation of the lesson, when the students realized that the game were not fair for both players.

\section{FINAL CONSIDERATIONS}

By observing the development of the activity described and the data collected over the course of the project, we noticed that, for any change to happen in the approach of teachers for teaching statistics, it is necessary to adopt some strategies to enable the exchange of experiences in the training process and experimentation in the classroom.

Another point which we believe is of fundamental importance is the shared analysis of the results. Capturing and understanding the movements of the teacher during a lesson is a complex task because the events that occur in this environment are difficult to repeat and are influenced by various factors such as social conditions, affective relationships between teachers and students, emotional state, and others. Sharing together, through lessons that are planned and developed in pairs, can enable teachers to provide new possibilities of action that may be passed along in the social structures in which they move. In our opinion, this teacher training strategy neither occurs nor works immediately. It will take a while for the process to stimulate comradery and trust among teachers and researchers, so that they feel safe and prepared to expose their ideas. Although we have not used this approach in our research, we understand that it is of fundamental importance for the evolution of approaches to teaching.

Regarding the workshop stage, it is recommended to perform different experiments. Teachers are not used to teaching statistics by collecting data. Typically, statistics lessons in primary education are developed through an approach that involves only reading and interpretation of data, which is clear in Alice's report. This approach to teaching deprives the student of the necessary knowledge to develop a critical and investigative sense in society. So it is also necessary to improve perceptions about the difference between math and statistics. It is important, in the processes of teacher training for statistics, to explore the difference between doing math and doing statistics. One approach that we believe would be efficient to explore this discussion is to start the training with questions that require data to be answered, without any a priori knowledge of the answers to these questions.

Investigative situations that involve probability usually begin by observation. In this case, the process of data processing must be done so that different experiments involving probabilistic situations are developed. Simulations using only dice, coins, and balls are not enough to explore 
these perceptions, because when we perform experiments with these objects, we already know the results. It is necessary to conduct experiments where the results are not known a priori. It is also extremely important to focus on the improvement of the knowledge of statistical content of teachers. Nobody teaches what he does not know. There is a consensus in the educational literature that knowledge about the content taught is an essential component of the teacher's competence.

The reports of the teachers participating in the research project about their frustrations regarding continuing education shows that it often does not prepare them to deal with problems relevant to their area, much less to allow the exchange of experiences. Oftentimes, continuing education in the area of mathematics offers models of lessons ready for teachers to follow as examples. Other times, the discussion becomes so open that those involved lose sight of the goal. We hear reports of teachers saying that even when they believe that the activities given in the textbooks are not appropriate, they end up using them, due to lack of choice and lack of time to prepare. At the end of the project, teachers stated that the best way to learn new teaching methodologies was through interaction with other teachers and with an appropriate theoretical support to the topic being studied.

Finally, another important element to be reported is that, although we have evidence that teachers overcame feelings of insecurity, a change in approach requires continuity, training cycles and more research to ensure the improvement of statistics education for teachers and students.

\section{REFERENCES}

Barbier, R. (2004). A pesquisa ação. Brasília, Brasil: Líber Livro Editora.

Batanero, C., \& Días, C. (2011). Estadística con proyectos. Granada, Spain: ReproDigital. Facultad de Ciencias

Batanero, C., \& Diaz, C. (2012). Training school teachers to teach probability: reflections and challenges. Chilean Journal of Statistics, 3(1), 3-13. Retrieved September 18, 2014, from, http://chjs.soche.cl/index.php?option $=$ com_content\&view $=$ article $\&$ id $=58 \& I t e m i d=56$.

Ministério da Educação. (1998). Parâmetros curriculares nacionais: Matemática. Brasília, Brasil: Author.

Pfannkuch, M. (2005). Probability and statistical inference: How can teachers enable learners to make connection? In G. A. Jones (Ed.), Exploring probability in school: Challenges for teaching and Learning (pp. 267-294). New York: Springer.

Pfannkuch, M. (2008). Training teachers to develop statistical thinking. In C. Batanero, G. Burrill, C. Reading, \& A. Rossman (Eds.), Teaching statistics in school mathematics. Challenges for teaching and teacher education. Proceedings of the Joint ICMI Study 18 and 2008 IASE Round Table Conference, Mexico: ICMI.

Soares, E. S., \& Goulart, M. I. M. (2008). Aulas Compartilhadas na formação de licenciados em matemática. Revista Brasileira de Educação, 13(38), 306-412.

Souza, L., \& Lopes C. E. (2011). O uso de simuladores e a tecnologia no ensino da estocástica. Bolema Boletim de Educação Matemática, 24(40), 659-677.

Souza, L., Faccio, A., \& Lopes C. (2014). Collaborative training for teaching probability and Statistics: empirical approaches and simulation with elementar school students. Ripem, 4(3), 87-103.

Stohl, H. (2005). Probability in teacher education and development. In G. A. Jones (Ed.), Exploring probability in school: Challenges for teaching and learning (pp. 297-324). New York: Springer.

Tripp, D. (2005). Pesquisa ação uma introdução metodológica. Educação e Pesquisa, 31(3), 443-466.

Wild, C., \& Pfannkuch, M. (1999). Statistical thinking in empirical enquiry. International Statistical Review, 67(3), 223-265. Retrieved September 18, 2014, from, http://www.stat.auckland.ac.nz/ iase/publications/isr/99.Wild.Pfannkuch.pdf. 